\title{
Aspectos fisiopatológicos do envelhecimento humano e quedas em idosos
}

\author{
Pathophysiological aspects of human aging and falls in the elderly \\ Aspectos fisiopatológicos del envejecimiento humano y caídas en adultos \\ mayores
}

\author{
Danuza Esquenazi*, Sandra R. Boiça da Silva, Marco Antônio M. Guimarães
}

\begin{abstract}
Resumo
O processo natural do envelhecimento envolve inúmeras transformações biológicas inerentes aos organismos e que ocorrem de maneira gradativa e premida por necessidades evolutivas. Este artigo aborda a forma como alterações anatômicas e fisiológicas próprias do envelhecimento estão estreitamente relacionadas ao risco de quedas nos idosos. Iniciamos mostrando como essas modificações, que começam no início da vida adulta, só se tornam importantes e funcionalmente significativas, devido à composição redundante dos sistemas orgânicos, quando o declínio atinge uma extensão considerável ou se associa ao aparecimento de patologias. A velocidade deste declínio depende de diversos fatores, genéticos e epigenéticos, que determinarão a resposta do organismo aos estímulos. Procuramos analisar os sistemas orgânicos mais envolvidos no risco de quedas no envelhecimento fisiológico, tais como: sistema visual e vestibular; sistema nervoso central (SNC) e cardiovascular; sistema musculoesquelético e ósseo. Dessa forma, tratamos inicialmente dos fatores responsáveis pela diminuição da capacidade de manter a estabilidade e a postura, a transposição de obstáculos, a acuidade visual e a função vestibular. Foi dado destaque especial às alterações dos sistemas musculoesquelético e ósseo, responsáveis pela locomoção e pela flexibilidade do corpo. A atrofia e a fraqueza muscular próprias da idade podem levar à sarcopenia, uma síndrome com graves consequências para os idosos e responsável por um número substancial de quedas e fraturas. Também discutimos como as modificações fisiológicas estruturais e funcionais do sistema cardiovascular que ocorrem no envelhecimento atuam como mecanismos adaptativos compensatórios às situações de sobrecarga. Fatores extrínsecos, tais como o uso de medicamentos diuréticos e anti-hipertensivos administrados com frequência em idosos com doenças cardiovasculares, também influenciam no deficit da estabilidade postural, contribuindo para a alta prevalência de quedas nessa população, podendo causar sérias consequências, inclusive a morte. Por fim, analisamos as alterações neurológicas observadas ao longo da vida, enfatizando os aspectos que se referem ao sistema mantenedor do equilibrio humano. Quando associadas a distúrbios motores, tais como os de força e equilíbrio, tais alterações muitas vezes são incapacitantes e apresentam um maior risco de morbimortalidade na população idosa, sobretudo se forem decorrentes de quedas.
\end{abstract}

Descritores: Envelhecimento; Fisiopatologia; Sistemas orgânicos; Acidentes por quedas.

\begin{abstract}
The natural aging process involves several biological changes that are inherent to organisms and occur on a gradual basis, due to evolutionary needs. This study focuses on the way age-related anatomical and physiological alterations are closely related to the risk of falls in the elderly. Initially, we show how these alterations, which start at the beginning of adult life, shall only acquire, due to the redundant composition of organic systems, relevance and functional significance when the decline either reaches a considerable extension or is associated with the emergence of pathologies. The speed of such a decline depends on several factors, both genetic and epigenetic ones, which shall determine the organism's response to stimuli. Our goal was to analyze the organic systems closely associated with the risk of falls in physiological aging, such as visual and vestibular system, central nervous system (CNS), cardiovascular system and musculoskeletal and bone systems. Thus, we initially addressed the


factors responsible for a reduction in the ability to keep stability and posture, the ability to transpose obstacles, visual acuity, and vestibular function. In particular, we highlighted the alterations of the musculoskeletal and bone systems, which are responsible for locomotion and flexibility. Age-related atrophy and muscular weakness may lead to sarcopenia, a syndrome with serious consequences for the elderly, which results in a significant number of falls and fractures. We also discuss how both structural and functional physiological modifications of the cardiovascular system during aging act as adaptive mechanisms for the compensation of further overload. Some extrinsic factors, such as the use of diuretic and antihypertensive drugs, which are often administrated to elderly affected by cardiovascular diseases, also influence the compromised postural stability, thus contributing to the high prevalence of falls in this population, possibly with serious consequences, including death. Finally, we analyze the neurological alterations observed during life emphasizing aspects related to the system which maintains human balance. In association with motor disturbances, such as in strength and balance, these changes use to lead to disabilities and offer a higher risk of morbidity and mortality among elderly, particularly when those result from falls.

Keywords: Aging; Physiopathology; Organic systems; Accidental falls.

\section{Resumen}

El proceso natural del envejecimiento implica numerosas transformaciones biológicas inherentes a los organismos, que ocurren de manera gradual e impulsada por necesidades evolutivas. Este artículo aborda cómo las alteraciones anatómicas y fisiológicas propias del envejecimiento están estrechamente relacionadas con el riesgo de caídas en adultos mayores. Comenzamos mostrando cómo esas modificaciones, que se dan en el inicio de la vida adulta, debido a la composición redundante de los sistemas orgánicos, sólo se vuelven importantes y funcionalmente significativas cuando el declive alcanza una extensión considerable o se asocia a la aparición de patologías. La velocidad de este declive depende de varios factores, genéticos y epigenéticos, que determinarán la respuesta del organismo a los estímulos. Intentamos analizar los sistemas orgánicos más concernidos con el riesgo de caídas por el envejecimiento fisiológico, tales como: sistema visual y vestibular; sistema nervioso central (SNC) y cardiovascular; sistema músculo esquelético y óseo. De esta forma, tratamos primeramente los factores responsables por la disminución de la capacidad para mantener la estabilidad y la postura, la transposición de obstáculos, la acuidad visual y la función vestibular. Se hizó énfasis en las alteraciones de los sistemas músculo esqueléticos y óseo, responsables por la locomoción y flexibilidad del cuerpo. La atrofia y la debilidad muscular propias de la edad pueden llevar a la sarcopenia, un síndrome con graves consecuencias para los adultos mayores y responsable por un número substancial de caídas y fracturas. También discutimos cómo las modificaciones fisiológicas estructurales y funcionales del sistema cardiovascular, que se dan en el envejecimiento, actúan como mecanismos adaptativos compensatorios en las situaciones de sobrecarga. Factores extrínsecos, como el uso de medicamentos diuréticos y antihipertensivos administrados con frecuencia en adultos mayores con enfermedades cardiovasculares, también influyen en el déficit de estabilidad postural, contribuyendo a la alta prevalencia de caídas en esta población, pudiendo causar serias consecuencias, incluso la muerte. Finalmente, analizamos las alteraciones neurológicas observadas a lo largo de la vida, enfatizando en los aspectos que se refieren al sistema que mantiene el equilibrio humano. Al asociarlas a transtornos motores, como fuerza y equilibrio, tales alteraciones muchas veces son incapacitantes y presentan un mayor riesgo de morbimortalidad en la población adulta mayor, sobre todo si fueron resultantes de caídas.

Palabras clave. Envejecimiento; Fisiopatología; Sistemas orgánicos; Accidentes por caídas.

\section{Introdução}

As alterações fisiológicas intrínsecas ao envelhecimento são sutis, inaptas a gerar qualquer incapacidade na fase inicial, embora, ao passar dos anos, venham a causar níveis crescentes de limitações ao desempenho de atividades básicas da vida diária.

Ao interagir com as informações visuais e somatossensoriais, o sistema vestibular produz rapidamente o alinhamento e o controle postural adequados a cada situação, sendo fundamental na manutenção do equilíbrio corporal. O processamento visual relacionado ao movimento e às relações espaciais é essencial ao controle postural. A visão é um processo complexo que envolve a integração das estruturas do olho, o controle motor e o controle neural. Sua importância reside na obtenção de informações sobre o ambiente e na orientação do movimento do corpo. Com o envelhecimento, o enfraquecimento do sistema visual favorece a ocorrência de quedas. ${ }^{1}$ Com relação ao sistema vestibular, sua principal função 
é fornecer ao SNC informações sobre a posição e o movimento da cabeça em relação à gravidade, gerando movimentos compensatórios dos olhos e respostas posturais. Apesar de automático e rápido, o controle postural também é flexível, capaz de adaptar-se a ambientes sensoriais diferentes e a limitações musculoesqueléticas. Além da cabeça, a postura do pescoço, do tronco e dos músculos antigravitacionais dos membros inferiores é controlada pelo sistema vestibular durante a movimentação e, ainda, na manutenção do alinhamento da massa corpórea sobre a base de suporte, os pés., ${ }^{2,3}$

Os sistemas musculoesquelético e ósseo têm importância crucial no processo de envelhecimento e merecem destaque. Os músculos esqueléticos são a maior massa tecidual do corpo humano, compreendendo cerca de $50 \%$ do peso corporal, razão pela qual são de suma importância na homeostasia bioenergética, tanto em repouso como em exercício. Sendo o principal local de transformação e armazenamento de energia, são o suporte primário dos sistemas cardiovascular e pulmonar. No caso de demanda muscular intensa, a hipertrofia de uso pode levar a um aumento ainda maior das fibras musculares. Por outro lado, na atrofia pelo desuso, as fibras ficam delgadas. A natureza plástica do tecido muscular é revelada pela multiplicidade de movimentos que o ser humano é capaz de realizar. Esses movimentos são controlados a partir do sistema nervoso e diferem de acordo com as características particulares dos vários tipos de fibras musculares. Um mesmo músculo, ou grupo muscular, pode responder e adaptar-se a um movimento de elevada coordenação, a um esforço curto e intenso, ou ainda a uma atividade prolongada. ${ }^{4}$ Alterações fisiológicas próprias da idade podem levar a uma atrofia e fraqueza muscular maior, a sarcopenia. Ademais, alterações endócrinas, nutricionais, mitocondriais, genéticas e comportamentais, como o sedentarismo ou a reduzida atividade física, são determinantes para a distinção do grau de sarcopenia, que varia muito entre os idosos, sendo mais acentuada nos membros inferiores.

O osso, fundamental por sua função de sustentação, é um tecido ativo continuamente remodelado com o intuito de manter sua resistência, conservar seu conteúdo mineral e curar-se de microfraturas, que ocorrem em consequência do contínuo deslocamento. Diversos fatores influenciam na constituição da massa óssea de um adulto. O primeiro dentre estes fatores é a herança genética, poligênica e para a qual colaboram igualmente genes oriundos de ambos os pais. ${ }^{5}$ Em seguida, enfileiram-se fatores ambientais dos quais participam alimentação e exercícios, de tal forma que a massa óssea presente no início do processo de envelhecimento será de capital importância para o idoso. Com taxa de remodelamento maior do que a do osso cortical, o trabecular é mais dinâmico e responsivo a fatores de crescimento, hormônios e minerais, sendo o que mais sofre com o envelhecimento. ${ }^{6}$ As alterações ósseas e musculares observadas com o aumento da idade são interdependentes. Ossos mais frágeis são apoiados por músculos mais fracos, o que leva a quedas e à sua consequência mais temida, as fraturas.

As alterações estruturais e funcionais do sistema circulatório que ocorrem no envelhecimento atuam como mecanismos adaptativos compensatórios às situações de sobrecarga. A hipertrofia da parede ventricular e a rigidez arterial são consequências desse processo, assim como a estreita correlação entre disfunção diastólica e idade avançada. ${ }^{7}$ Aliadas ao uso habitual de medicamentos para controlá-las, essas alterações favorecem a ocorrência de quedas, tão comum em idosos.

Sob o aspecto histológico, anatômico e morfofuncional do sistema neurológico, o central e o periférico são distintos, porém compartilham um processo fisiológico comum: o envelhecimento neuronal. O córtex cerebral é uma região formada por bilhões de células nervosas agrupadas, que estão relacionadas a funções complexas como motricidade, sensibilidade e os mecanismos cognitivos correlatos, como memória, linguagem, aprendizagem e consciência. ${ }^{8}$ Com o avançar da idade, o indivíduo apresenta deficiências no controle genético da produção de proteínas estruturais, de enzimas e dos fatores neurotróficos. Esse deficit, por sua vez, repercute de maneira negativa na função das células nervosas e da glia, tornando mais difíceis a neurogênese, a plasticidade, a condução e a transmissão dos impulsos nervosos. Com isso, são gerados deficit consideráveis nos equilíbrios estático e dinâmico. ${ }^{9}$

Abaixo, discutiremos mais detalhadamente 
como as alterações anatômicas e fisiológicas dos sistemas acima citados ocorrem no envelhecimento humano bem-sucedido e, ainda, como podem contribuir com a fisiopatologia relacionada à propensão de quedas em idosos.

\section{Alterações visuais}

As alterações morfológicas e fisiológicas sofridas pelas estruturas do olho ao longo do envelhecimento acabam por interferir na acuidade visual dos idosos. Em geral, entre a quarta e quinta décadas da vida, essas alterações geram os primeiros sintomas oftalmológicos, e o mais comum é a diminuição da capacidade de acomodação ou de focalização de objetos próximos (presbiopia). Com o passar dos anos, ocorre a diminuição do campo visual periférico, da sensibilidade ao contraste, da discriminação das cores, da capacidade de recuperação após exposição à luz, da adaptação ao escuro e da noção de profundidade. Como a córnea torna-se menos sensível, suas lesões podem passar despercebidas no envelhecimento fisiológico. Entretanto, a atrofia do epitélio pigmentar da retina e a degeneração da porção central da sua mácula, a fóvea, são as causas mais graves de perda visual em idosos. Além disso, o tamanho da pupila diminui e ela se torna mais lenta nas respostas à escuridão ou à luminosidade intensa; o cristalino torna-se esbranquiçado, menos flexível e levemente opaco, resultado do agrupamento de componentes proteicos da lente. Relacionada com a idade, a catarata é uma causa de cegueira em uma escala global, envolvendo influências genéticas e ambientais. Nela, ocorrem modificações pós-translacionais e acúmulo de cromóforos fluorescentes, aumentando a susceptibilidade ao dano oxidativo, embora esse processo comece a partir da quarta década de vida. À medida que a área opaca aumenta, a visão torna-se cada vez mais comprometida. ${ }^{10}$ Anatomicamente, a perda de gordura em volta dos olhos provoca seu afundamento dentro da órbita e a redução da força dos músculos extraoculares dificulta a rotação dos olhos e a movimentação nos planos vertical e horizontal. Vários estudos têm mostrado que o enfraquecimento da visão provocado pelo envelhecimento fisiológico reduz a estabilidade postural e aumenta significativamente o risco de quedas e fraturas em idosos. ${ }^{11,12}$

\section{Alterações do sistema vestibular}

A partir da quarta década de vida, são observadas alterações anatômicas e fisiológicas no sistema vestibular que se acentuam com o passar do tempo. São processos degenerativos que levam à redução gradual na densidade dos receptores e no número de células receptoras de algumas estruturas do sistema. A principal consequência do envelhecimento natural do sistema vestibular é a degeneração do reflexo vestíbulo-ocular, sendo manifestação clássica de sua falência o desequilíbrio quando há rotação do corpo, que acarreta o desvio da marcha. ${ }^{13}$ Além dos episódios de tontura e vertigem, outro grande problema surge em consequência dos frequentes eventos de desequilíbrio na população geriátrica: as quedas. Esse risco aumenta consideravelmente com o avançar da idade (acima dos 80 anos), quando associado a outras doenças crônicas como o diabetes $f$, e ainda pela polifarmácia, comum na velhice. As vestibulopatias em idosos costumam estar associadas a outros sistemas responsáveis pelo controle postural, como a visão e as sensações proprioceptivas. Estas se caracterizam por sinais enviados ao SNC por receptores sensoriais presentes nos músculos, tendões e nas articulações, que aferem ao movimento e à estabilidade do corpo. Assim, a conduta terapêutica, normalmente centrada em exercícios de reabilitação vestibular, é significativamente abrangente. ${ }^{14}$

\section{Alterações musculoesqueléticas e}

\section{ósseas}

No ser humano, o sistema muscular alcança sua maturação plena entre 20 e 30 anos de idade. Os diferentes tipos de músculos são formados por grupamentos distintos de fibras musculares, cujo diâmetro aumenta gradualmente durante o crescimento fisiológico, podendo variar entre 10 e $100 \mu \mathrm{m} .{ }^{15}$ A partir dos 30 anos de vida, a densidade muscular diminui, ocorre perda gradual e seletiva das fibras esqueléticas que dão lugar a tecido adiposo e colágeno. Após os 35 anos, há alteração natural na cartilagem articular que, associada às alterações biomecânicas adquiridas ou não, provocam ao longo da vida degenerações diversas que podem levar à diminuição da função locomotora e da flexibilidade, acarretando maior 
risco de lesões. De fato, observam-se alterações da estrutura do colágeno como redução do comprimento das cadeias de condroitina na cartilagem articular. Porém, é importante salientar que tais alterações não indicam que a pessoa tenha uma doença articular degenerativa ou venha a apresentá-la, e sim que existe uma possibilidade aumentada de que a cartilagem articular possa sofrer lesões decorrentes de obesidade, trauma, doença metabólica, fatores hereditários e pelo desgaste próprio do tempo de vida. ${ }^{16}$

Com o avanço da idade, a perda muscular é progressiva, porém, não apresenta um comportamento linear em função do tempo, sendo mais pronunciada no sexo feminino do que no masculino, estimando-se uma perda de aproximadamente $5 \%$ por década até os 50 anos, e a partir daí, 10\% por década até os 80 anos..$^{15}$ Nos idosos, há uma importante diminuição na proporção de fibras musculares anaeróbicas de contração rápida em comparação com as fibras aeróbicas de contração lenta. Prejudicado pela fraqueza muscular progressiva, o idoso tende a posturas viciosas irregulares e compensatórias, mas que impõem um agravamento crescente às estruturas do aparelho locomotor, levando à lentificação da marcha e perda de equilíbrio, fatores esses que induzem a uma maior tendência a quedas e fraturas.

A sarcopenia, perda de massa muscular esquelética e de força associada ao envelhecimento, acarreta morbidade e mortalidade significativas. A força muscular não depende apenas da massa e, portanto, a avaliação de ambas é mandatória na avaliação do idoso. A partir dos 75 anos, o grau de sarcopenia é um dos indicadores da chance de sobrevivência do indivíduo. ${ }^{17}$

As causas para a sarcopenia são múltiplas, sendo as principais a disfunção mitocondrial, alterações endócrinas, distúrbios nutricionais, imobilidade, inatividade física e doenças neurodegenerativas. Quanto aos mecanismos hormonais associados à sarcopenia, podemos citar a ativação do sistema renina-angiotensina e o consequente aumento dos níveis de angiotensina II, implicados na atrofia muscular por levarem ao aumento dos níveis da E3 ligase atrogina e, assim, à proteólise. ${ }^{18}$ Se levarmos em conta a prevalência da hipertensão arterial no idoso, este pode ser um mecanismo relevante, contribuindo para a sarcopenia. Hormônios que levam ao anabolismo muscular, como a insulina, o fator de crescimento semelhante à insulina 1 (IGF-1), hormônios tireoidianos e a testosterona promovem acúmulo de proteína e a hipertrofia muscular e decaem com a idade, favorecendo o decréscimo da massa muscular. ${ }^{18} \mathrm{~A}$ resistência à insulina, que aumenta com o envelhecimento, é mais um dos fatores de propensão à sarcopenia, sendo esta diretamente proporcional ao conteúdo de gordura intracelular. ${ }^{19}$

As mitocôndrias, a "usina de força" dos músculos, decaem em número e capacidade funcional com o envelhecimento. ${ }^{20}$ Mecanismos possíveis para a perda progressiva destas organelas são a lesão do DNA mitocondrial e o deficit das células na remoção das mitocôndrias danificadas. O DNA mitocondrial é mais susceptível a lesões do que o nuclear, devido à proximidade com as espécies reativas de oxigênio geradas na mitocôndria, por ser um DNA não enovelado como o DNA nuclear (assim mais exposto a danos químicos) e porque os mecanismos de reparo do DNA mitocondrial não são tão eficazes quanto os do DNA nuclear. ${ }^{21}$ Para o descarte de mitocôndrias disfuncionais, é fundamental a autofagia, processo de degradação intracelular, o qual decresce com o envelhecimento. Além das mitocôndrias disfuncionais, outra característica do envelhecimento é o acúmulo de proteínas alteradas. ${ }^{22} \mathrm{O}$ acúmulo dessas proteínas indutoras do estresse do retículo endoplasmático e morte celular tem sido ligado à morte das células pancreáticas no diabetes tipo 2 e dos neurônios. ${ }^{23}$

Novamente, o processo de autofagia degradando depósitos de proteínas intracelulares, além das mitocôndrias disfuncionais, parece ser fundamental para retardar o envelhecimento, prevenindo o estresse do retículo endoplasmático e um estímulo à apoptose e liberação excessiva de espécies reativas de oxigênio, oriundas das mitocôndrias disfuncionais. Além disso, a autofagia degrada gotículas lipídicas intracelulares, um dos mais precoces marcadores da resistência à insulina e da perda muscular com o envelhecimento. ${ }^{24,25}$

A restrição calórica sem desnutrição, que parece ser até o momento o único mecanismo comprovado como capaz de retardar o envelhecimento em várias espécies e não apenas no homem, é um indutor da autofagia, tornando a célula mais capaz de livrar-se de seu "lixo". O estímulo gerado pela restrição calórica à autofagia e à degradação proteica via proteassomos deve 
ser enfatizado como um possível mecanismo para a sua ação. Ademais, o exercício aeróbico diminui o dano mitocondrial associado ao envelhecimento, o que corrobora a noção de que os efeitos antienvelhecimento da restrição calórica e do exercício físico passam pelo "bem-estar" das mitocôndrias. ${ }^{26,27}$

Ao lado dos tecidos muscular e cartilaginoso, o tecido ósseo, em constante processo de remodelação (formação pelos osteoblastos e reabsorção pelos osteoclastos), sofre alterações consideráveis ao longo do envelhecimento, levando à osteopenia fisiológica. ${ }^{27}$

O esqueleto tem três funções importantes: sustentação para o sistema musculoesquelético; proteção de órgãos internos vitais e reservatório metabólico para a hematopoiese e a homeostase do cálcio. Cerca de $90 \%$ da massa óssea é alcançada na segunda década de vida e o pico de massa óssea ocorre em torno dos 35 anos de idade. As alterações relacionadas principalmente à diminuição da densidade mineral e à perda óssea iniciam em torno da quarta década de vida. A atrofia óssea causada pelo envelhecimento não é homogênea, pois, até os 50 anos de idade, perde-se sobretudo osso trabecular, gerando uma osteopenia reversível. Após essa idade, perde-se, principalmente, osso cortical e a perda óssea é irreversível. ${ }^{28}$

Tanto os osteoclastos quanto os osteoblastos possuem receptores de estrogênio, e, devido à redução do estrogênio na menopausa, a osteopenia é mais acelerada e perceptível no sexo feminino, sendo associada a uma atividade osteoclástica aumentada. Já na perda óssea relacionada com a idade, o processo é mais lento e resulta de hipoatividade osteoblástica. Sem dúvida, a osteopenia é um fator de risco para fraturas em idosos, mas não é patognomônica da osteoporose. ${ }^{28}$ Nos homens, o osso trabecular se torna progressivamente mais fino com a idade, não havendo a perda de contato entre as porções de osso trabecular, como ocorre nas mulheres após a menopausa. ${ }^{28,29}$

No que diz respeito à microarquitetura óssea, uma característica do envelhecimento é a diminuição na estatura, com perda média aproximada de $2 \mathrm{~cm}$ por década, a partir dos 60 anos, independentemente do gênero. Tal alteração se manifesta de forma mais acentuada na coluna vertebral do que nos membros, e decorre principalmente de modificações dos elementos do tecido conjuntivo dos discos intervertebrais, que perdem a capacidade de absorver água, tornando os ligamentos de elastina menos distensíveis e propensos a sofrer fragmentações sucessivas. A estabilidade dos segmentos móveis e a sustentação da coluna vertebral também apresentam alterações no idoso, pois a função dos ligamentos anteriores e posteriores da coluna vertebral sofre redução com o avanço da idade. Isto afeta diretamente a diminuição da capacidade de realizar tensão de "repouso" sobre a coluna vertebral e a ausência da força de tensão dos ligamentos, que contribuem para a adoção da postura flexionada para frente comum nos idosos. A consequente doença degenerativa articular do idoso provoca alterações ósseas e da superfície articular, como os osteófitos resultantes da osteoartrite, a radiculopatia pela compressão dos nervos e redução na atividade da miosina adenosino-trifosfase (ATPase) das fibras musculares, levando à fraqueza muscular e ao desequilíbrio, proporcionando um aumento na incidência de quedas. ${ }^{30}$

Dessa forma, pode-se concluir que, nos idosos, a redução do comprimento da coluna vertebral, as alterações degenerativas das estruturas vertebrais que são forçadas a suportar a carga dos discos e a ausência da força de tensão dos ligamentos irão contribuir para a adoção da postura flexionada para frente e propiciar as quedas.

\section{Alterações cardiovasculares}

Indivíduos saudáveis e com idade avançada sofrem uma série de alterações fisiológicas no coração, especialmente estruturais e funcionais, fundamentais para melhor adaptação às necessidades inerentes ao processo do envelhecimento. O coração é constituído por células musculares, os cardiomiócitos, moléculas de matriz extracelular, destacando-se o colágeno e células intersticiais cardíacas, tais como fibroblastos e células endoteliais. Por tratar-se de células terminalmente diferenciadas, a identificação recente de células-tronco residentes no coração revelou que os cardiomiócitos são repostos, mas não na proporção ideal para recuperação de função alterada consequente a eventuais perdas. ${ }^{31}$

Com o envelhecimento, observa-se frequentemente aumento na espessura da parede ventricular, caracterizado por um decréscimo no número 
de cardiomiócitos, que se tornam hipertróficos e, ainda, pelo aumento do conteúdo de colágeno. O metabolismo mitocondrial das espécies reativas de oxigênio altera-se, contribuindo para maior secreção de colágeno e indução de apoptose das células musculares lisas da parede arterial, o que leva ao aumento da rigidez aórtica. ${ }^{32} \mathrm{~A}$ alteração da elasticidade aórtica colabora para hipertrofia do ventrículo esquerdo, disfunção diastólica e insuficiência cardíaca congestiva. A maior massa ventricular esquerda faz com que o peso do coração aumente de 1 a 1,5 g por ano. ${ }^{33}$

Apesar das conhecidas alterações na função diastólica que normalmente acompanham o envelhecimento, existe controvérsia em relação à função sistólica. A maioria dos estudos, feitos com indivíduos saudáveis, aponta para manutenção da função sistólica e estreita correlação entre disfunção diastólica e idade avançada. ${ }^{7}$ As células intersticiais cardíacas também sofrem alterações com o envelhecimento, tendo participação importante na patogênese das doenças cardiovasculares, como a aterosclerose. As espécies reativas de oxigênio derivadas das mitocôndrias contribuem para a manutenção de pequeno grau de inflamação crônica no leito vascular, ativando as vias de sinalização redox. Recentes estudos apontam para o importante papel das espécies reativas de oxigênio na indução de apoptose das células endoteliais e no desenvolvimento do fenótipo senescente destas células, podendo levar ao comprometimento da integridade dos vasos e da angiogênese. ${ }^{34}$

No envelhecimento, é comum a redução da habilidade em alterar a frequência cardíaca de maneira adequada em resposta a situações de estresse, provavelmente devido à menor resposta dos receptores beta-adrenérgicos. ${ }^{35}$ Ocorre ainda redução na resposta autonômica ao estresse, incluindo diminuição do barorreflexo, o que torna habitual a variação da pressão arterial com mudanças posturais, contribuindo assim para a elevada ocorrência de quedas em idosos. As propriedades eletrofisiológicas do coração também se alteram no envelhecimento e levam à maior ocorrência de arritmias, observando-se aumento na prevalência (tanto de taqui como de bradiarritmias) após os 60 anos de idade. Nesta população são comuns as disfunções sinusais e os bloqueios atrioventriculares, aumentando a incidência de implantação de marca-passos. A ocorrência de focos ectópicos ventriculares e supraventriculares e as alterações das propriedades dos canais iônicos cardíacos contribuem para a maior ocorrência das arritmias, assim como para a variação dos parâmetros farmacodinâmicos e farmacocinéticos dos medicamentos antiarrítmicos habitualmente utilizados. ${ }^{36}$

Portanto, sendo frequentes as alterações cardiovasculares que acompanham o envelhecimento, é comum o uso de diversos medicamentos como diuréticos, anti-hipertensivos, antiarrítmicos e vasodilatadores. Paradoxalmente, o tratamento medicamentoso contribui para a elevada ocorrência de quedas nos idosos e não é rara a suspensão do seu uso. Por exemplo, embora seja recomendável para idosos com fibrilação atrial o uso de anticoagulantes, o risco de quedas nessa população restringe sua aplicação. ${ }^{37}$ Segundo o Ministério da Saúde do Brasil, cerca da metade dos idosos que fazem uso de anti-hipertensivos e diuréticos sofre uma ou mais quedas no prazo de um ano. ${ }^{38}$

\section{Alterações neurológicas}

Diversas modificações fisiológicas e estruturais ocorrem no cérebro ao longo da vida. São alterações multifatoriais, muitas das quais contribuem para a perda da força e desequilíbrio em pessoas idosas e são potencializadas quando associadas a processos patológicos. Desde o nascimento, a totalidade de neurônios necessários ao funcionamento do organismo já estão presentes. Aos dois anos de idade, o cérebro atinge $80 \%$ do seu tamanho adulto. $\mathrm{O}$ amadurecimento cerebral decorre da multiplicação de células da glia, gerando aumento no depósito de mielina nas fibras nervosas, assim como novas conexões. O volume e o peso do cérebro declinam com a idade, a uma taxa aproximada de 5\% por década após os 40 anos, observando-se uma acentuação no declínio a partir da sétima década de vida. ${ }^{39}$

O córtex cerebral é uma complexa região formada por bilhões de células nervosas relacionadas a funções complexas como motricidade, sensibilidade e mecanismos cognitivos. Dessa forma, o córtex é uma das regiões mais importantes do SNC. O sistema nervoso periférico (SNP) também desempenha uma importante função sensório- 
motora sobre o sistema mantenedor do equilíbrio por meio de impulsos nervosos para a periferia, especialmente para os músculos esqueléticos. As constituições histológicas, anatômicas e morfofuncionais dos SNC e SNP diferem de forma significativa. Porém, tais estruturas compartilham um processo fisiológico comum: o envelhecimento neuronal. ${ }^{40}$

O comprometimento da regulação da homeostase do cálcio e do mecanismo de proteção antioxidante são duas causas importantes da degeneração neuronal observadas durante o envelhecimento normal e na neurodegeneração. $\mathrm{Na}$ verdade, qualquer alteração no transporte ou no armazenamento do cálcio, independentemente de seu grau, acarreta consequências significativas para o envelhecimento. E seu aumento excessivo causa lipólise, proteólise, mudanças na fosforilação proteica, perda da integridade citoesquelética e morte celular. ${ }^{41}$

Nos distúrbios neurodegenerativos progressivos, como nas doenças de Parkinson (DP) e Alzheimer (DA), a lesão neuronal pode ser causada por pequenas alterações da homeostase do cálcio mantidas durante longos períodos de tempo. Há alguns anos, surgiu uma "hipótese do cálcio" para explicar o avanço do envelhecimento cerebral, sugerindo que os mecanismos celulares responsáveis pela manutenção dos níveis de cálcio citoplasmático têm um papel fundamental no envelhecimento. Além disso, as alterações sustentadas da homeostase do cálcio podem fornecer uma via comum para as alterações patológicas observadas nas doenças neurodegenerativas. ${ }^{42}$

Ao lado das alterações da homeostase do cálcio, a disfunção mitocondrial tem estreita relação com a morte neuronal. As mitocôndrias são de suma importância na geração de adenosina-5'-trifosfato (ATP), no sequestro do excesso de cálcio citoplasmático e na "desintoxicação" dos neurônios causadas por espécies reativas de oxigênio. ${ }^{43}$

Sabe-se que fatores genéticos controlam a susceptibilidade à desregulação do cálcio e do estresse oxidativo, e a falha desses mecanismos pode causar morte neuronal. Mutações gênicas provocam alterações nas proteínas e enzimas que deveriam sequestrar os radicais livres (superóxido dismutase, glutato peroxidase) e regular a homeostase do cálcio (calmodulina). A degradação proteica intracelular daí decorrente parece ser realizada por várias vias, desde a via dependente dos lisossomos até a via dependente do cálcio. Além disso, cada via "trata" as proteínas de maneira diferente, dependendo de sua sequência de aminoácidos. ${ }^{44}$ Ainda, a disfunção mitocondrial dependente de cálcio provoca defeitos morfológicos e no tráfego dos neurônios, sendo crítica para a degeneração neuronal observada na DP, na DA e na doença de Huntington. ${ }^{45}$

Tomados em conjunto, podemos afirmar que alterações fisiopatológicas características de algumas doenças neurodegenerativas como a DP, também são responsáveis por quedas na população idosa. Esses pacientes apresentam distúrbios motores frequentes, como tremor e rigidez, levando a dificuldades no equilíbrio. Diferente da DP, que consiste em um distúrbio, sobretudo motor, a DA é caracterizada por alterações cognitivas inerentes à atrofia cerebral e à formação de placas amiloides e emaranhados neurofibrilares. Alterações nas reações de equilíbrio e mesmo a ocorrência de quedas são comuns nos estágios avançados da doença, embora em menor frequência do que nos indivíduos parkinsonianos. ${ }^{46}$

\section{Conclusões}

O envelhecimento é um processo evolucionário, no qual se destacam o metabolismo, seus danos nas células e sistemas e as patologias decorrentes. O metabolismo, processo de sustentação da vida, gera toxinas, principalmente em células permanentes em estágios pós-mitóticos, como os neurônios tão necessários para memória de longa duração, e os cardiomiócitos, que facilitam a hipertrofia compensatória do coração. Paradoxalmente, os danos nas células são causados por produtos biológicos tóxicos. Esses fatos constituem-se na ponta do iceberg que permeia as incapacidades do indivíduo idoso em todos os sistemas orgânicos. Dentre essas incapacidades, a perda da integração ósteo-muscular-cerebral é a maior responsável pelas quedas e suas deletérias consequências.

\section{Referências}

1. Sung $\mathrm{CH}$, Chuang JZ. The cell biology of vision. J Cell Biol. 2010;190(6):953-63.

2. Hain TC, Ramaswamy TS, Hillman MA. Anatomia e Fisiologia do Sistema Vestibular Normal. In: Herdman 
SJ. Reabilitação Vestibular. $2^{\text {a }}$ ed. São Paulo: Editora Manole; 2002.

3. Kandel ER, Schwartz JH. Percepção. In: Kandel ER, Schwartz JH, Jessell TM. Princípios de Neurociência. $4^{\text {a }}$ ed. São Paulo: Editora Manole; 2003. p. 492-572.

4. Sherwood L. Human Physiology: from cells to systems. 7th ed. USA: Brooks/Cole Eds.; c2010. Chapter 8, Muscle physiology; p. 257-64.

5. Ralston SH. Genetics of osteoporosis. Ann NY Acad Sci. 2010;1192:181-9.

6. Clarke B. Normal bone anatomy and physiology. Clin J Am Soc Nephrol. 2008;3(Suppl. 3):S131-9.

7. Chaudhary KR, El-Sikhry H, Seubert JM. Mitochondria and the aging heart. J Geriatr Cardiol. 2011;8(3):159-67.

8. Naveh-Benjamin M, Cowan N, Kilb A, Chen Z. Age-related differences in immediate serial recall: dissociating chunk formation and capacity. Mem Cognit. 2007;35(4):724-37.

9. Bear MF, Commors BW, Paradiso MA. Neurociências: desvendando o sistema nervoso. $2^{\mathrm{a}}$ ed. Porto Alegre: Artes Médicas; 2002. 856 p.

10. Michael R, Bron AJ. The ageing lens and cataract: a model of normal and pathological ageing. Philos Trans R Soc Lond B Biol Sci. 2011;366(1568):1278-92.

11. Lord SR. Visual risk factors for falls in older people. Age Ageing. 2006;35(S2):ii42-5.

12. Macedo BG, Pereira LS, Gomes PF, Silva JP, Castro AN. Impacto das alterações visuais nas quedas, desempenho funcional, controle postural e no equilíbrio dos idosos: uma revisão de literatura. Rev Bras Geriat Gerontol. 2008;11(3):419-32.

13. Jahn K, Zwergal A, Schniepp R. Gait disturbances in old age: classification, diagnosis, and treatment from a neurological perspective. Dtsch Arztebl Int. 2010;107(17):306-15.

14. Horak FB. Postural orientation and equilibrium: what do we need to know about neural control of balance to prevent falls? Age Ageing. 2006;35(S2):7-11.

15. Davies MR. Muscle. In: Davies A, Blakeley AGH, Kidd C. Human Physiology. Philadelphia: Elsevier; 2001.

16. Freemont AJ, Hoyland JA. Morphology, mechanisms and pathology of musculoskeletal ageing. J Pathol. 2008;211(2):252-9.

17. Larsson L, Ramamurthy B. Aging-related changes in skeletal muscle. Mechanisms and interventions. Drugs Aging. 2000;17(4):303-16.

18. Sukhanov S, Semprun-Prieto L, Yoshida T, Michael Tabony A, Higashi Y, Galvez S, et al. Angiotensin II, Oxidative Stress and Skeletal Muscle Wasting. Am J Med Sci. 2011;342(2):143-7.
19. Yki-Järvinen H. Fat in the liver and insulin resistance. Ann Med. 2005;37(5):347-56.

20. Lanza IR, Nair KS. Regulation of skeletal muscle mitochondrial function: genes to proteins. Acta Physiol (Oxf). 2010;199(4):529-47.

21. Hipkiss AR. Mitochondrial dysfunction, proteotoxicity, and ageing: causes or effects, and the possible impact of NAD+ controlled protein glycation. Adv Clin Chem. 2010;50:123-50.

22. Katayama T, Imaizumi K, Manabe T, Hitomi J, Kudo $\mathrm{T}$, Tohyama M. Induction of neuronal death by ER stress in Alzheimer's disease. J Chem Neuroanat. 2004;28(1-2):67-78.

23. Fartoux L, Poujol-Robert A, Guéchot J, Wendum D, Poupon R, Serfaty L. Insulin resistance is a cause of steatosis and fibrosis progression in chronic hepatitis C. Gut. 2005;54(7):1003-8.

24. Singh R, Kaushik S, Wang Y, Xiang Y, Novak I, Komatsu M, et al. Autophagy regulates lipid metabolism. Nature. 2009;458(7242):1131-5.

25. Cuervo AM. Calorie restriction and aging: the ultimate "cleansing diet". J Gerontol A Biol Sci Med Sci. 2008;63(6):547-9.

26. Qi Z, He J, Su Y, He Q, Liu J, Yu L, et al. Physical exercise regulates $\mathrm{p} 53$ activity targeting $\mathrm{SCO} 2$ and increases mitochondrial COX biogenesis in cardiac muscle with age. PLoS One. 2011;6(7):211-40.

27. Carvalho-Filho E. Fisiologia do Envelhecimento. In: Papaléo Netto M. Gerontologia: a velhice e o envelhecimento em visão globalizada. São Paulo: Atheneu; 2002. p. 60-70.

28. Matsudo SM, Matsudo VKR, Barros Neto TL. Impacto do envelhecimento nas variáveis antropométricas, neuromotoras e metabólicas da aptidão física. Rev Bras Ciênc Mov. 2000;8(4):21-32.

29. Martin A, David V, Laurence JS, Schwarz PM, Lafer EM, Hedge AM, et al. Degradation of MEPE, DMP1, and release of SIBLING ASARM peptides (minhibins): ASARM peptide(s) are directly responsible for defective mineralization in HYP. Endocrinology. 2008;149(4):1757-72.

30. Nair KS. Aging muscle. Am J Clin Nutr. 2005;81(5):953-63.

31. Bergmann O, Bhardwaj RD, Bernard S, Zdunek S, Barnabé-Heider F, Walsh S, et al. Evidence for cardiomyocyte renewal in humans. Science. 2009;324(5923):98-102.

32. Zhou RH, Vendrov AE, Tchivilev I, Niu XL, Molnar $\mathrm{KC}$, Rojas $\mathrm{M}$, et al. Mitochondrial oxidative stress in aortic stiffening with age: the role of smooth muscle cell function. Arterioscler Thromb Vasc Biol. 2012;32(3):745-55.

33. Olivetti G, Melissari M, Capasso JM, Anversa P. 
Cardiomyopathy of the aging human heart. Myocyte loss and reactive cellular hypertrophy. Circ Res. 1991;68(6):1560-8.

34. Dai DF, Rabinovitch PS, Ungvari Z. Mitochondria and cardiovascular aging. Circ Res. 2012;110(8):1109-24.

35. De Meersman RE. Heart rate variability and aerobic fitness. Am Heart J. 1993;125(3):726-31.

36. Lee HC, Huang KT, Shen WK. Use of antiarrhythmic drugs in elderly patients. J Geriatr Cardiol. 2011;8(3):184-94.

37. Wetzel U, Hindricks G, Piorkowski C. Atrial fibrillation in the elderly. Minerva Med. 2009;100(2):145-50.

38. Ministério da Saúde. Envelhecimento e Saúde da Pessoa Idosa. Cadernos de Atenção Básica ${ }^{0}$ 19. Série A. Normas e Manuais Técnicos. Brasília: Ministério da Saúde, 2006.

39. Mrak RE, Griffin ST, Graham DI. Aging-associated changes in human brain. J Neuropathol Exp Neurol. 1997;56(12):1269-75.

Recebido: 08/03/2013

Revisado: 26/10/2013.

Aprovado: 17/11/2013.
40. Shankar SK. Biology of aging brain. Indian J Pathol Microbiol. 2010;53(4):595-604.

41. Gleichmann M, Mattson MP. Neuronal calcium homeostasis and dysregulation. Antioxid Redox Signal. 2011;14(7):1261-73.

42. Cali T, Ottolini D, Brini M. Mitochondrial $\mathrm{Ca}(2+)$ and neurodegeneration. Cell Calcium. 2012;52(1):73-85.

43. Nicholls DG. Oxidative stress and energy crises in neuronal dysfunction. Ann NY Acad Sci. 2008;1147:53-60.

44. Sonntag KC. MicroRNAs and deregulated gene expression networks in neurodegeneration. Brain Res. 2010;1338:48-57.

45. Kumar A, Bodhinathan K, Foster T. Cell selective susceptibility to calcium dysregulation during brain aging. Front Aging Neurosci. 2009;1:2.

46. Doherty KM, van de Warrenburg BP, Peralta MC, Silveira-Moriyama L, Azulay JP, Gershanik OS, et al. Postural deformities in Parkinson's disease. Lancet Neurol. 2011;10(6):538-49.

\section{Danuza Esquenazi}

Departamento de Patologia e Laboratórios. Faculdade de Ciências Médicas. Universidade do Estado do Rio de Janeiro. Rio de Janeiro, RJ, Brasil.

\section{Sandra R. Boiça da Silva}

Departamento de Patologia e Laboratórios. Faculdade de Ciências Médicas. Universidade do Estado do Rio de Janeiro. Rio de Janeiro, RJ, Brasil.

\section{Marco Antônio M. Guimarães}

Departamento de Patologia e Laboratório. Faculdade de Ciências Médicas. Universidade do Estado do Rio de Janeiro. Rio de Janeiro, RJ, Brasil. 